\title{
Batu Bata Ringan dengan Filler Paduan Serat Ijuk Aren dan Sekam Padi terkarbo- nasi
}

\author{
La Ode Musa Rachmat ${ }^{1, *}$, Sulaiman ${ }^{1}$, Ibrahim ${ }^{2}$, La Ode Ahmad Nur Ramadhan ${ }^{3}$, Laode A. Kadir ${ }^{3}$ \\ Program Studi Teknik Sipil, Universitas Sulawesi Tenggara, Kendari ${ }^{1}$, Sekolah Menengah Kejuruan Negeri 6 Kendari, Kendari, Jurusan \\ Kimia, Universitas Halu Oleo, Kendari ${ }^{3}$ \\ Koresponden*,Email: laodemusarachmat@gmail.com
}

\begin{tabular}{|c|c|c|}
\hline & Info Artikel & Abstract \\
\hline Diajukan & 29 Juni 2021 & During this time, the existence of carbonated palm sugar and rice husk has not been utilized \\
\hline Diperbaiki & 25 Juli 2021 & to the maximum, especially in non-structural construction in the manufacture of lightweight \\
\hline Disetujui & 02 Agustus 2021 & $\begin{array}{l}\text { bricks. Theoretically, the addition of fiber in the manufacture of lightweight bricks with palm } \\
\text { fiber filler and carbonated rice husk can increase the compressive strength of lightweight brick } \\
\text { pairs for non-structural purposes. This research aims to determine clay composition from palm } \\
\text { fiber and carbonated rice husk on light brick (mechanical properties). The results show that } \\
\text { the best composition between brick and palm fiber filler and carbonated rice husk was } 4.500 / 50 \\
\text { palm sugar/450 rice husk composition. It also has a density of } 950 \mathrm{~kg} / \mathrm{m}^{3} \text {, a compressive } \\
\text { strength of } 3,012 \mathrm{MPa} \text {, and tight morphology. Meanwhile, light bricks without filler obtained }\end{array}$ \\
\hline \multicolumn{2}{|c|}{$\begin{array}{l}\text { Keywords: light brick, carbonated rice } \\
\text { husk, palm fiber, compressive strength. }\end{array}$} & $\begin{array}{l}\text { a density of } 1250 \mathrm{~g} / \mathrm{cm} 3 \text { and porous morphology. The increase in the composition of } \\
\text { carbonated rice husks tends to increase its mechanical strength. This makes the bricks lighter } \\
\text { and improves their mechanical properties. }\end{array}$ \\
\hline
\end{tabular}

Abstrak

Selama ini keberadaan ijuk aren dan sekam padi terkarbonasi belum di manfaatkan secara maksimal terutama dalam dunia konstruksi yang bersifat non struktural dalam pembuatan batu bata ringan. Secara teoritis penambahan serat dalam pembuatan batu bata ringan dengan filler serat ijuk aren dan sekam padi terkarbonasi mampu menambah kuat tekan pada pasangan batu bata ringan untuk keperluan non struktural, dimana secara terbatas material serat dapat di gunakan dari bahan-bahan alami. Penelitian ini bertujuan unntuk mengetahui pengaruh komposisi tanah liat dari serat ijuk aren dan sekam padi terkarbonasi terhadap karakteristik batu bataringan (berat jenis, sifat mekanik). Hasil penelitian menunjukkan bahwa komposisi terbaik antara batu bata dan filler serta ijuk aren dan sekam padi terkarbonasi adalah komposisi $4.500 / 50$ ijuk/450 sekam, dengan massa jenis $950 \mathrm{~g} / \mathrm{cm}^{3}$, kuat tekan 3,012 MPa. Sedangkan batu bata ringan tanpa filler diperoleh massa jenis $1250 \mathrm{~g} / \mathrm{cm}^{3}$ dan morfologi yang berpori. Peningkatan komposisi sekam padi terkarbonasi cenderung meningkatkan kekuatan mekaniknya, hal ini menja-

Kata kunci: bata ringan, sekam padi dikan batu bata lebih ringan dan memperbaiki sifat mekaniknya.

mempunyai kemampuan tarik yang cukup sehingga diharapkan dapat mengurangi retak dinding maupun akibat beban [5].

Salah satu serat alami yang masih sedikit dieksplorasi oleh para peneliti adalah serat aren. Serat tersebut secara tradisional digunakan dalam berbagai aplikasi yang mencakup dari sapu, kuas cat, filter dasar tangki septik, filter air jernih, keset, karpet, tali, bantal kursi/sofa, sarang ikan untuk menetaskan telurnya, dan untuk atap karena kekuatan dan daya tahannya [6]. Karakteristik serat aren ini adalah hal yang penting jika serat tersebut mampu dioptimalkan penggunaannya sebagai penguat komposit [7].

Pada penelitian ini, selain serat ijuk, juga digunakan abu sekam padi yang ditambahkan dalam campuran membentuk paduan serat alami sebagai filler. Abu sekam padi merupakan serat alami dengan kandungan silika yang cukup tinggi 
berkisar diatas $80 \%$ [8]. Aplikasinya sebagai bahan aditif dalam pembuatan batu bata ringan meningkatkan kuat tekan, mengecilkan porositas dan mengurangi kemampuan adsorbsi air sampai $15 \%$ [9].

Upaya untuk meningkatkan penggunaan bahan alami yang melimpah dalam kehidupan sehari-hari terutama penggunaan serat sebagai penguat (filler) komposit terus berkembang [10]. Hal ini didasari oleh jumlah serat alam yang berlimpah, dapat diperbaharui dan didaur ulang serta ramah lingkungan [11]. Selain itu, metode memadukan serat ijuk dan sekam padi terkarbonasi sebagai filler pada bahan konstruksi batu bata ringan dapat dijadikan metodologi baru untuk menghasilkan bahan konstruksi dengan sifat mekanik yang lebih baik.

\section{Metode}

Tahap pembuatan batu bata ringan dilakukan melalui penghalusan tanah liat dimana digunakan sebanyak 4500 gram sebagai material dasar pembuatan batu bata di campur dengan paduan filler dengan komposisi 0 gram sekam :500 gram ijuk, sampai dengan 500 gram sekam: 0 gram ijuk, 50 gram sekam: 450 gram ijuk, 100 gram sekam: 400 gram ijuk, 150 gram sekam: 350 gram ijuk, 200 gram sekam: 300 gram ijuk, 250 gram sekam: 250 gram ijuk, 300 gram sekam: 200 gram ijuk, 350 gram sekam: 150 gram ijuk, 400 gram sekam: 100 gram ijuk,450 gram sekam:50 gram ijuk

\section{Pemasakan dan Pembakaran Batu Bata Ringan}

Dalam tahapan pemasakan, semua campuran dengan komposisi tersebut di atas dihomogenkan dengan penambahan air, pembentukan dan siap dicetak. Hasil pencetakan dikeringkan pada suhu ruang penyimpanan selama seminggu. Selanjutnya cetakan batu bata dibakar pada suhu sekitar $750{ }^{\circ} \mathrm{C}$ selama $3 \times 24$ jam sampai berwarna merah. Batu bata dikarakterisasi melalui pengukuran massa jenis, kuat tekan dengan alat uji tekan, morfologi dengan mikroskop optik [6].

\section{Uji Kuat Tekan}

Uji tekan terhadap contoh batu bata ringan dilakukan untuk memperoleh informasi kekuatan mekanik terhadap batu bata ringan yang dihasilkan. Dalam pengujian menggunakan alat uji tekan Panairsan, digunakan standar ASTM C109. Untuk mengetahui tegangan hancur dari material uji tersebut, maka dilakukan perhitungan menggunakan Persamaan 1 .

$$
\begin{aligned}
& \text { Kuat Tekan }=\frac{P}{A} \\
& \text { dengan: } \\
& \mathrm{P}=\text { beban tekan }(\mathrm{N}) \\
& \mathrm{A}=\text { Luas bidang tekan }\left(\mathrm{mm}^{2}\right)
\end{aligned}
$$

\section{Uji Densitas}

Untuk pengukuran densitas digunakan standar ASTM C 642 dan dihitung dengan persamaan 2.

$$
P p c=\frac{m s}{m g-m k} x \text { densitas }
$$

dengan:

$\mathrm{Ppc}=\operatorname{densitas}\left(\mathrm{g} / \mathrm{cm}^{3}\right)$

$\mathrm{ms}=$ massa sampel kering $(\mathrm{g})$

$\mathrm{mg}=$ massa sampel digantung dalam air (g)

$\mathrm{mk}=$ massa kawat penggantung $(\mathrm{g})$

\section{Hasil dan Pembahasan}

Analisis Komposisi Batu Bata Ringan

\begin{tabular}{|c|c|c|c|c|c|c|c|c|}
\hline \multirow[t]{2}{*}{ No } & $\begin{array}{c}\text { Kode } \\
\text { Sampel }\end{array}$ & $\mathrm{FeO}$ & $\mathrm{Na}_{2} \mathrm{O}$ & MgO & $\mathbf{A l}_{2} \mathrm{O}_{3}$ & $\mathrm{SiO}_{2}$ & $\mathrm{CaO}$ & $\begin{array}{c}\text { Minera } \\
\text { Lain }\end{array}$ \\
\hline & (g) & $(\%)$ & (\%) & (\%) & $(\%)$ & (\%) & $(\%)$ & $(\%)$ \\
\hline 1 & $\begin{array}{c}\text { Batu } \\
\text { bata } \\
\text { original }\end{array}$ & 4,44 & 0,56 & 0,54 & 19,29 & 72,74 & 0,30 & $<0,01$ \\
\hline 2 & $\begin{array}{l}\text { Sekam } \\
\text { Batu }\end{array}$ & 1,02 & 0,74 & 0,28 & $<0,01$ & 83,58 & 2,54 & $<0,01$ \\
\hline 3 & $\begin{array}{c}\text { bata }(0 \\
\text { ijuk: } 500 \\
\text { sekam }\end{array}$ & 2,69 & 0,71 & 0,28 & 16,92 & 79,60 & 0,20 & $<0,01$ \\
\hline 4 & $\begin{array}{c}\text { Batu } \\
\text { bata } \\
(100 \\
\text { ijuk:400 } \\
\text { sekam) }\end{array}$ & 2,81 & 0,66 & 0,14 & 16,86 & 79,49 & 0,28 & $<0,01$ \\
\hline 5 & $\begin{array}{c}\text { Batu } \\
\text { bata (50 } \\
\text { ijuk: } 450 \\
\text { sekam) }\end{array}$ & 2,8 & 0,68 & 0,31 & 16,86 & 78,41 & 0,22 & $<0,01$ \\
\hline
\end{tabular}

Hasil analisis komposisi batu bata ringan dengan menggunakan XRF analyzer (ED-XRF Epsilon 3) terlihat pada Tabel 1.

Tabel 1. Hasil analisis komposisi batu bata ringan

Uji analisa XRF ini dilakukan untuk mengetahui perbedaan kandungan mineral komposit batu bata original dengan batu bata ringan buatan yang dipadukan dengan filler serat ijuk dan abu sekam padi. Batu bata original mengandung mineral dominan yaitu $\mathrm{Al}_{2} \mathrm{O} 3, \mathrm{SiO}_{2}, \mathrm{FeO}, \mathrm{CaO}$, dan sedikit $\mathrm{TiO}_{2}$ yang berfungsi sebagai perekat. Mineral ini hampir sama dengan komponen batu bata ringan buatan berbagai macam variasi komposisi. Batu bata ringan buatan tidak menunjukkan perubahan angka komposisi kimia yang signifikan seperti yang ditunjukkan pada Tabel 1. Warna batu bata ringan yang dihasilkan berasal dari unsur Fe oksida yang membuat batu bata berwarna sedikit merah bata [12].

\section{Fotomikrografi Komposit}

Pengujian fotomikografi terhadap sampel batu bata ringan dilakukan dengan menggunakan mikroskop optik. Hasil pengujian mikroskop optik untuk material komposit batu bata ringan dengan filler paduan ijuk dan sekam padi terkarbonasi terlihat pada Gambar 1.

Gambar 1 menunjukkan perbandingan hasil fotomikrografi dari beberapa komposit. Komposit tanpa penambahan filler sekam padi (Gambar 1d) dan komposit perbandingan filler ijuk : sekam; 100 : 400 (Gambar 1a), menunjukkan 
terdapat banyak void atau rongga yang terbentuk di dalam komposit. Hal ini dapat disebabkan oleh wettability yang kurang baik sehingga menyebabkan matriks tidak dapat membasahi filler dengan sempurna akibatnya terbentuklah rongga/void antara matriks dan filler. Selain itu, void ini dapat terlihat akibat proses manufaktur komposit yang kurang sempurna ketika dilakukan proses pencetakan dan dapat menyebabkan terperangkapnya gelembung udara dan membentuk void/rongga di dalam komposit tersebut [13].

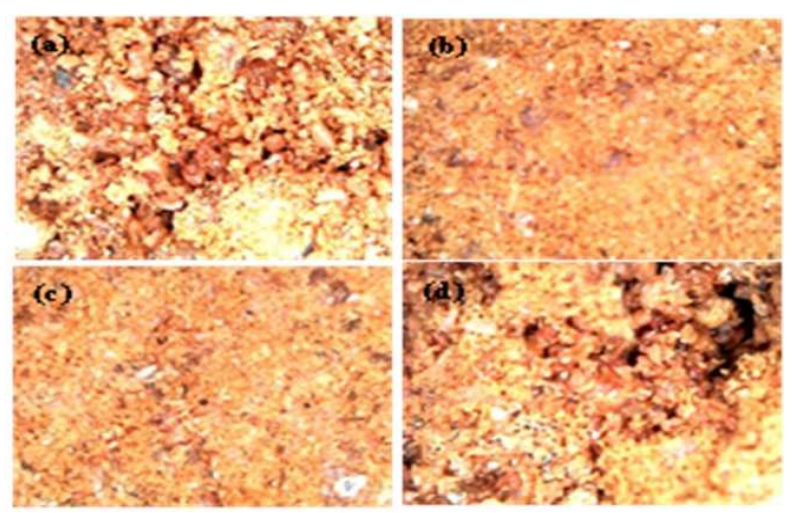

Gambar 1. Hasil fotomikrografi komposit batu bata ringan (a) perbandingan filler ijuk : sekam; 100 : 400, (b) perbandingan filler ijuk : sekam; $50: 450$, (c) perbandingan filler ijuk : sekam; 0 : 500, (d) perbandingan filler ijuk : sekam; 500 : 0, dengan perbesaran 50x

Sementara itu, komposit dengan penambahan filler 50 ijuk/450 sekam (Gambar 1b) dan filler 0 ijuk/500 sekam (Gambar 1c) menunjukkan hasil fotomikrografi yang sangat baik, hal ini ditandai dengan keberadaan void/rongga jauh lebih sedikit jika dibandingkan dengan Gambar 1a dan Gambar 1d. Berkurangnya rongga/void dapat mempengaruhi beberapa sifat fisik seperti penyerapan air dan densitas [14]. Ikatan antara matriks dan filler yang baik dan persebarannya yang merata sama-sama akan menaikkan sifat mekanik komposit yang baik. Semakin baik interfacial bonding dan persebaran filler yang terdapat dalam komposit maka akan menghasilkan sifat mekanik yang lebih tinggi [14].

\section{Uji Densitas}

Pengujian densitas dilakukan melalui cara menghitung massa dan volume dari tiap spesimen agar dapat diketahui massa jenisnya. Hasil pengujian densitas dari batu bata ringan dengan filler dari paduan serat ijuk dan abu sekam padi yang telah dibuat ditunjukkan pada Gambar 2.

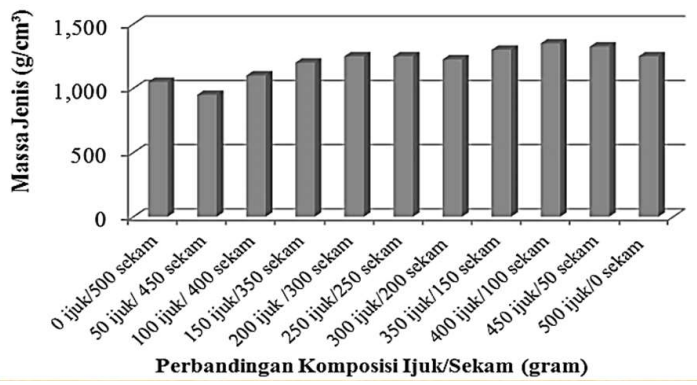

Gambar 2. Hasil uji densitas komposit batu bata ringan berbagai variasi komposisi

Berdasarkan Gambar 2, terlihat bahwa variasi komposisi sangat mempengaruhi densitas komposit yang dihasilkan. Pada komposit dengan penambahan filler 400 ijuk/100 sekam (gram) memiliki densitas paling tinggi yakni sebesar 1.350 $\mathrm{g} / \mathrm{cm}^{3}$ sedangkan komposit dengan penambahan filler 50 ijuk/450 sekam (gram) memiliki densitas paling rendah yakni sebesar $950 \mathrm{~g} / \mathrm{cm}^{3}$. Secara umum dari Gambar 2, semakin tinggi komposisi serat ijuk yang ditambahkan maka densitas komposit yang dihasilkan akan semakin besar pula begitu pula sebaliknya semakin besar komposisi sekam padi makan akan meningkatkan densitas komposit. Hal ini sesuai dengan konsep rule of mixture dimana sifat dari suatu komposit, salah satunya densitas, sangat dipengaruhi oleh sifat dari material penyusunnya. Semakin besar fraksi volume material penyusun dengan densitas yang lebih besar, maka komposit yang terbentuk cenderung memiliki nilai densitas yang tiggi juga begitu pula sebaliknya [15].

\section{Uji Kuat Tekan}

Pengujian kuat tekan dilakukan untuk mengetahui kekuatan kompresi dari komposit batu bata ringan dengan penambahan filler serat ijuk dan sekam padi. Dengan mengetahui kekuatan kompresi dari material komposit, maka dapat dijadikan pertimbangan komposit yang dibuat untuk dijadikan bahan bangunan seperti ubin, paving block, dinding, papan partikel, dan lain-lain. Hasil uji kompresi yang dilakukan terlihat pada Gambar 3.

Berdasarkan hasil pengujian kuat tekan pada komposit terlihat bahwa penambahan serat ijuk dan sekam padi berpengaruh terhadap nilai kekuatan kompresi pada komposit yang telah dibuat. Kekuatan kompresi paling rendah yaitu sebesar 0,21 MPa pada variasi komposisi penambahan filler 450 ijuk/50 sekam (gram) dan penambahan filler 500 ijuk/0 sekam (gram) sedangkan nilai kekuatan kompresi paling tinggi yaitu sebesar 3,012 $\mathrm{MPa}$ pada variasi komposisi dengan penambahan filler $50 \mathrm{ijuk} / 450$ sekam (gram). 


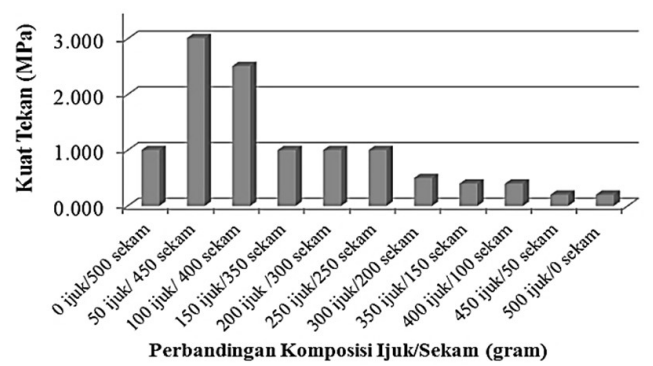

Gambar 3. Hasil uji kuat tekan komposit batu bata ringan berbagai variasi komposisi

Gambar 3 menunjukkan bahwa penambahan serat ijuk dan sekam padi akan meningkatkan kekuatan kompresi dari komposit sampai pada komposisi tertentu. Penambahan kedua filler tersebut secara bersamaan menghasilkan kekuatan kompresi maksimum pada variasi 50 gram ijuk/450 gram sekam padi.

Kenaikan kekuatan kompresi pada penambahan 50 gram ijuk/450 gram sekam padi karena adanya ikatan yang baik antara matriks (semen) dan filler (serat ijuk/abu sekam padi) sehingga menyebabkan nilai kuat tekan pada batu bata ringan bertambah. Selain ikatan yang baik, serat ijuk memiliki kekuatan patah yang tinggi (High Fracture Strength), sehingga membuat bahan uji menjadi padat dan membuatnya memiliki kekuatan yang cukup tinggi dan memiliki kekuatan untuk menahan tekanan.

\section{Simpulan}

Batu bata ringan dengan filler paduan serat ijuk aren dan sekam padi terkarbonasi telah berhasil dibuat. Paduan ini mengandung mineral dominan seperti $\mathrm{Al}_{2} \mathrm{O} 3, \mathrm{SiO}_{2}, \mathrm{FeO}$, dan $\mathrm{CaO}$. Komposisi terbaik antara batu bata dan filler serta ijuk aren dan sekam padi terkarbonasi adalah komposisi 4.500/50 ijuk/450 sekam, dengan massa jenis $950 \mathrm{~g} / \mathrm{cm}^{3}$, kuat tekan 3,012 MPa. Sedangkan batu bata ringan tanpa filler diperoleh massa jenis $1250 \mathrm{~g} / \mathrm{cm}^{3}$ dan hasil uji tekan 0,21 MPa dengan morfologi yang berpori. Peningkatan komposisi sekam padi terkarbonasi cenderung meningkatkan kekuatan paduan, hal ini menjadikan batu bata lebih ringan dan meningkat sifat mekaniknya.

\section{Daftar Pustaka}

[1] A. O. Perdana, A. S. Wahyuni, and Elhusna, "Pengaruh Penambahan Serat Ijuk Terhadap Kuat Tarik Belah Beton Dengan Faktor Air Semen 0,5," vol. 7, no. 2, pp. 7-12, 2015.

[2] D. Bachtiar, S. M. Sapuan, E. S. Zainudin, A. Khalina, and K. Z. M. Dahlan, “ The tensile properties of single sugar palm ( Arenga pinnata ) fibre," IOP Conf. Ser.
Mater. Sci. Eng., vol. 11, p. 012012, 2010.

[3] I. Adha and H. Ali, "Studi Kuat Tekan Batu Bata Menggunakan Bahan Additive ( Abu Sekam Padi , Abu Ampas Tebu dan Fly Ash )," vol. 3, no. 3, pp. 541-552, 2015.

[4] M. R. Ishak, S. M. Sapuan, Z. Leman, M. Z. A. Rahman, and U. M. K. Anwar, "Characterization of sugar palm (Arenga pinnata) fibres Tensile and thermal properties," in Journal of Thermal Analysis and Calorimetry, 2012, vol. 109, no. 2, pp. 981-989.

[5] W. Sarjono, "Pengaruh Penambahan Serat Ijuk Pada Kuat Tarik Campuran Semen-Pasir Dan Kemungkinan Aplikasinya," J. Tek. Sipil Univ. Atma Jaya Yogyakarta, vol. 8, no. 2, pp. 159-169, 2008.

[6] A. K. Samlawi, Y. F. Arifin, and P. Y. Permana, "Pembuatan Dan Karakterisasi Material Komposit Serat Ijuk (Arenga Pinnata) Sebagai Bahan Baku Cover Body Sepeda Motor," Info-Teknik, vol. 18, no. 2, pp. 289-300, Jan. 2018.

[7] S. Kappenthuler and S. Seeger, "From resources to research - a framework for identification and prioritization of materials research for sustainable construction," Mater. Today Sustain., vol. 7-8, p. 100009, 2020.

[8] S. Hesami, S. Ahmadi, and M. Nematzadeh, "Effects of rice husk ash and fiber on mechanical properties of pervious concrete pavement," Constr. Build. Mater., vol. 53, pp. 680-691, 2014.

[9] F. Estuyulianto, M. H. Mukti, and T. Sipil, "Pengaruh Penambahan Abu Sekam Padi pada Kuat Tekan Beton Campuran 1 pc: 2 ps : 3 kr," no. December 2015, pp. 74-79, 2012.

[10] N. M. T. K, H. G. Sunil, D. Rani, and A. Kumar, "Manufacturing of building blocks using Hempcrete," vol. 02, no. 07, pp. 62-73, 2016.

[11] T. D. Garrett, H. E. Cardenas, and J. G. Lynam, "Sugarcane bagasse and rice husk ash pozzolans: Cement strength and corrosion effects when using saltwater," Curr. Res. Green Sustain. Chem., vol. 1-2, no. April, pp. 7-13, 2020.

[12] W. Zamrudy and A. R. Hakim, "Karakteristik Batu Bata Tanah Liat Dengan Filler Sekam Padi,” vol. 3, pp. 21-25.

[13] R. Sidik, "Studi Pengaruh Penambahan Polypropylene dan Low Density Polyethylene Terhadap Sifat Fisik dan Mekanik Wood Plastic Composite Untuk Aplikasi Genteng Ramah Lingkungan,” 2018.

[14] H. Prakusya, S. T. Wicaksono, and I. Purbawanto, "Pengaruh Komposisi Filler Limbah Papan Semen 
Partikel," J. Tek. Its, vol. 8, no. 2, 2019.

[15] W. Fitri and M. Mora, "Pengaruh Persentase Serbuk Ampas Tebu terhadap Sifat Fisik dan Mekanik Papan Semen Partikel," J. Fis. Unand, vol. 7, no. 4, pp. 367373, 2018. 
